\title{
DIVISON XII / COMMISSION 5 / WORKING GROUP LIBRARIES
}

\author{
CHAIR \\ CO-CHAIR \\ MEMBERS
}

\author{
Uta Grothkopf \\ Fionn Murtagh \\ Christina Birdie, Marsha Bishop, \\ Laurence Bobis, Donna J. Coletti, \\ Brenda G. Corbin, Monique Gomez, \\ Halima Naimova
}

TRIENNIAL REPORT 2006 - 2009

\section{Introduction}

The IAU Working Group on Libraries was officially recognized for the first time in the Transactions of the IAU XXIA Reports on Astronomy (McNally 1991), but librarians were involved in Commission 5 activities before that (largely due to the efforts of George A. Wilkins, president of the Commission from 1982 to 1988, see Transactions of the IAU XXA Reports on Astronomy, Swings 1988). Wayne Warren (NASA GSFC, MD, USA) and Helen Knudsen (Calech, CA, USA) were the group's first chairpersons, Brenda Corbin (U.S. Naval Observatory) became Helen Knudsen's successor in 1990. Since 1996, Fionn Murtagh (School of Computer Science, Queen's University of Belfast, Northern Ireland) and Uta Grothkopf (European Southern Observatory, Germany) have been co-chairs.

The WG on Libraries aims to facilitate better cooperation between astronomers and librarians. The publication paradigm continues to shift from printed material to electronic formats for scientific literature, leading to an evolved concept of library services and information access. Librarians are taking on new and diversified roles. While demands for traditional services continue, the importance of accessibility and archiving of older materials is widely recognized. Long-term solutions, developed cooperatively by publishers, scientists and librarians, are needed in order to guarantee future access to today's knowledge.

Some projects of interest to both librarians and astronomers (though not developed under the auspices of this group) are the International Astronomy Meetings List, a database of Reports of Observatories, listings of IAU colloquia and astronomical newsletters, the Directory of Astronomy Librarians and Libraries, a book reviews database, digitization projects of historical documents, maintenance of core lists of astronomy books and astronomy and physics journals and the mailing lists Astrolib and EGAL. The IAU Thesaurus, compiled by R.M. \& R.R. Shobbrook under the auspices of the IAU, may prove to be of use as a tool for automated information retrieval, provided that necessary updates can be implemented. The IAU funded the first Library and Information Services in Astronomy (LISA) conference, held in 1988 in Washington, DC, USA (IAU Colloquium No. 110) and supported the second (IAU Technical Workshop, Garching, Germany, 1995). Since then, LISA has developed into a series of conferences which are held at regular intervals; LISA VI will be held in Pune, India, in February 2010. 


\section{Membership developments}

In 2007 and 2008, we were happy to welcome two new members to our Working Group: Marsha Bishop, (National Radio Astronomy Observatory, USA), and Christina Birdie (Indian Institute of Astrophysics, India). The role of librarians among the IAU is becoming ever more visible: by now, five members (Brenda Corbin, Donna Coletti, Peter Hingley, Monique Gomez and Uta Grothkopf) have been accepted by the IAU as full members rather than consultants, which has previously been the typical status of librarians among the IAU.

\section{Activities within the past triennium}

During the IAU XXVI General Assembly in Prague, Czech Republic, August 2006, the Working Group on Libraries, organized a Business Meeting jointly with the Working Group on Publishing.

- Françoise Genova (CDS) described the Use and Validation of the IAU Astronomy Thesaurus in Ontologies, a collaboration of French computing departments in the frame of the Massive Data in Astronomy project.

- Uta Grothkopf (ESO) and Brenda Corbin (USNO) presented a summary of the $L i$ brary and Information Services in Astronomy. V(LISA V) conference,held in Cambridge, MA, USA, June 2006.

- Brenda Corbin also gave an Overview of Observatory Archives with a special focus on the setup and maintenance of the archives of Lowell Observatory, the National Radio Astronomy Observatory and Yerkes Observatory in the USA.

- Guenther Eichhorn (ADS) presented an update on the ADS Abstract Service and reported on the (close) Cooperation between the ADS and Libraries, both in the early days of the ADS as well as nowadays.

- Karel A. van der Hucht (IAU Assistant General Secretary) explained The New Structure of the IAU Proceedings Series: after the reorganization of IAU symposia and colloquia (with the colloquia having been merged into the symposia series), the WG Publishing is now pleased to report much shorter production times for proceedings volumes.

- Uta Grothkopf reported on the Use of Bibliometrics by Observatories, based on a questionnaire distributed among major observatories.

Slides of the individual presentations can be found at <www.eso.org/sci/libraries/ IAU-WGLib/iau06/>.

Subsequent to the colloquium Future professional communication in Astronomy, held in Brussels, Belgium, in June 2007 (Heck \& Houziaux 2007), Terry Mahoney (Instituto de Astrofisica de Canarias, Spain), and a group of librarians, among them Karen Moran (Royal Observatory Edinburgh, UK), Shireen Davis (South African Astronomical Observatory, Cape Town), and Monique Gomez (Insituto de Astrofisica de Canarias, Spain) wrote a Declaration Concerning the Evolving Role of Libraries in Research Centres, also called the Manifesto. This document "reflects the concerns of its drafters at the increasing invisibility of research libraries vis-á-vis recent accelerated changes in publishing and reader-access technology". The document is meant to raise discussion about these topics and, ultimately, the authors hope that it might be considered for adoption as official IAU policy. The declaration has been published in the December 2007 issue of The Observatory (Mahoney et al. 2007), and in the July 2008 issue of the IAU Information Bulletin (Mahoney et al. 2008).

In January 2008, the ESO librarians Uta Grothkopf and Christopher Erdmann compiled a document on Open Access - state of the art. The paper gives a brief introduction 
to open access (OA), helps readers to distinguish between open access and open access publishing, summarizes variations in publishers' approaches towards OA, and reports on the situation in astronomy. Recent developments in Europe and the U.S. are briefly explained. The document has been published in the July 2008 issue of the IAU Information Bulletin (Grothkopf \& Erdmann 2008).

\section{Closing remarks}

The Working Group on Libraries intends to get involved at the IAU XXVII General Assembly, to be held in Rio de Janeiro, Brazil, August 2009. Sessions may focus on data access and preservation, science metrics, and the role of librarians in fostering research.

The web site of the Working Group can be found at <www.eso.org/libraries/IAUWGLib/>.

Uta Grothkopf \& Fionn Murtagh chair $\&$ co-chair of the Working Group

\section{References}

Grothkopf, U. \& Erdmann, C. 2008, IAU Information Bulletin, No. 102, p. 64

Heck, A. \& Houziaux, L. (eds.) 2007, Future Professional Communication in Astronomy, Proc. Coll. Brussels, 10-13 June 2007 (Bruxelles: Acad. Royale de Belgique)

Mahoney, T. J., et al. 2007, The Observatory, 127, 401

Mahoney, T. J., et al. 2008, IAU Information Bulletin, No.102, p. 70

McNally, D. (ed.) 1991, Reports on Astronomy, Transactions of the IAU XXIA (Dordrecht: Kluwer Acad. Publ.)

Swings, J.-P. (ed.) 1988, Reports on Astronomy, Transactions of the IAU XXA (Dordrecht: Kluwer Acad. Publ.) 